American Journal of Agricultural and Biological Sciences 5 (2): 242-246, 2010

ISSN 1557-4989

(C) 2010 Science Publications

\title{
Effect of Lactate Treatments on Survival of Food-Borne Pathogens in Frozen Shrimp (Penaeus merguiensis)
}

\author{
Alireza Shirazinejad and Noryati Ismail \\ Food Technology Division, School of Industrial Technology, \\ University Sains Malaysia, 11800 Minden, Penang, Malaysia
}

\begin{abstract}
Problem statement: Sodium lactate treatments were evaluated for reducing population of pathogenic bacteria such as Salmonella enteritidis, E. coli O157:H7, Vibrio parahaemolyticus and Vibrio cholerae, inoculated on frozen shrimp (Penaeus merguiensis). Approach: Fresh shrimp were inoculated with the above pathogens, separately, at level of $10^{5} \mathrm{CFU} \mathrm{\textrm {g } ^ { - 1 }}$ and appliedin sodium lactate solutions (NaL: $0.5 \%$ and $2.5 \% \mathrm{v} / \mathrm{v}$ ) and $1 \%$ Lactic Acid (LA) plus $1.5 \%$ sodium lactate (as buffered lactic acid) followed by freezing. The samples were stored at $-18^{\circ} \mathrm{C}$ and antimicrobial and organoleptical effects of the treatments were evaluated after 90 days. Results: Results indicated that there was synergistic effect between frozen storage combined with $2.5 \%(\mathrm{v} / \mathrm{v})$ buffered LA which resulted in a great significant reductions $(\mathrm{p} \leq 0.05)$ approximately 5.11, 5.39, 2.86 and $2.66 \log$ $\mathrm{CFU} \mathrm{\textrm {g } ^ { - 1 }}$ in the number of colonies of $V$. cholerae, V. parahaemolyticus, S. enteritidis and E. coli $\mathrm{O} 157: \mathrm{H} 7$, respectively. On the other hand, although the effectiveness of sodium lactate increase with increased concentrations, however, there are sensory problems associated with increasing concentrations of sodium lactate. Conclusion/Recommendations: Therefore, $1.5 \%$ (v/v) sodium lactate plus $1.0 \%(\mathrm{v} / \mathrm{v})$ Lactic Acid (buffered LA) was recommended to be used for frozen shrimps without adversely interfering with sensory quality.
\end{abstract}

Key words: Frozen storage, shrimp, food-borne pathogens, lactic acid, sodium lactate

\section{INTRODUCTION}

The effects of organic acids and their salts as antibacterial agents in reducing the bacterial colonies during storage in food industries, especially in meat industries such as beef, poultry and pork have been largely studied (Bogaert and Naidu, 2000). These preservatives are Generally Recognized As Safe (GRAS) by the US Food and Drug Administration and used as food blends, sprays or dips. Sodium and/or potassium lactate at levels of $2-4 \%$ have been shown to act as bacteriostatic agents against pathogenic bacteria such as L. monocytogenes, E. coli O157:H7 and Salmonella when incorporated into a variety of RTE meat products (Shelef, 1994; Stekelenburg and KantMuermans, 2001). Papadopoulos et al. (1991) injected beef top rounds with $0-0.4 \%$ sodium lactate, cooked and vacuum packaged the roasts. The aerobic plate counts for control meat increased from 2.7-8.0 $\log \mathrm{CFU} \mathrm{cm}^{-2}$ after 84 days of storage, but the plate counts of treated roasts increased to $6.5 \log \mathrm{CFU} \mathrm{cm} \mathrm{cm}^{-2}$ in the same period (Papadopoulos et al., 1991).
Nowadays consumer's demands have increased for the use of natural preservatives having high organoleptical qualities, extending the shelf-life and improving the safety of seafood products. Lactic acid and sodium lactate are natural preservatives that could be used directly in the washing process, glazing water and/or in the freezing process to control microbial contamination and keeping the quality of fresh and frozen products.

The purpose of the present study was to determine the effect of sodium lactate treatments and buffered lactic acid on population of Salmonella enteritidis, E. coli O157:H7, Vibrio cholerae and Vibrio parahaemolyticus, inoculated on shrimps in combination with freezing.

\section{MATERIALS AND METHODS}

Preparations of materials and bacterial culture: Freshly-caught shrimps (Penaeus merguiensis) used in this study were procured in Penang, Malaysia. The shrimps were placed in ice before being taken to the laboratory. Vibrio cholerae, Vibrio parahaemolyticus, Salmonella enteritidis and Escherichia coli O157:H7

Corresponding Author: Noryati Ismail, Food Technology Division, School of Industrial Technology,

University Sains Malaysia, 11800 Minden, Penang, Malaysia Tel: +6 046532220 Fax: +6 046573678 
were obtained from the Microbiology Laboratory, School of Industrial Technology, University Sains Malaysia. All the bacterial strains were maintained on Trypticase Soy Agar (TSA, Merck, Germany) slants at $4^{\circ} \mathrm{C}$. In the case of Vibrio parahaemolyticus, TSA containing $3.0 \%(\mathrm{w} / \mathrm{w})$ sodium chloride was used.

Inoculation of samples with bacterial strains: A loopful of each obtained species was transferred aseptically into $10 \mathrm{~mL}$ (placed into $20 \mathrm{~mL}$ universal bottle) sterile Alkaline Peptone Water (APW; Merck, Germany) (V. cholerae), APW plus $3.0 \%$ (w/v) $\mathrm{NaCl}$ (for V. parahaemolyticus) and lactose broth as growth culture for $S$. enteritidis as well as E. coli and followed by cultivating separately $24 \mathrm{~h}$ at $37^{\circ} \mathrm{C}$ in shaker incubator. After incubation, each species was counted by using spread plate method (Food and Drug Administration, 2001). The number of colony-forming units per ml was considered as initial inoculum load to inoculate into fresh shrimp samples. Therefore, $1 \mathrm{~mL}$ of pure overnight culture in the specimen broth (approximately $10^{7} \mathrm{CFU} \mathrm{mL}^{-1}$ ) were inoculated separately by surface inoculation on $50 \mathrm{~g}$ shrimps, conducted in laminar air flow hood at room temperature and under aseptic conditions. Inoculated shrimps were placed onto sterilized polypropylene containers and refrigerated at $4{ }^{\circ} \mathrm{C}$ for 24 to allow conditioning of bacteria in the samples.

Freezing and frozen storage of inoculated shrimps: Sodium lactate solutions (PURASAL, Singapore) which were used in the block water with $0 \%$ (as control), $0.5 \%$ and $2.5 \%(\mathrm{v} / \mathrm{v})$ concentrations were poured into the Polypropylene (PP) containers containing $50 \mathrm{~g}$ inoculated shrimps in 1 to 4 ratios (1 part of shrimp: 4 parts of solution) and were properly labeled. Solutions covered all surface of the whole shrimps (Head-on). Then the containers were blast frozen at $-40^{\circ} \mathrm{C}$ to freeze within five $\mathrm{h}$. After blast freezing the PP containers with frozen blocks were unloaded and were placed into deep freezer at $-18^{\circ} \mathrm{C}$ for 90 days storage. At the end of storage the samples were removed and thawed overnight in the chiller before analysis. Microbiological procedures for counting the four species of bacteria were determined following standard methods of FDA's Bacteriological Analytical Manual (BAM) Methods (Food and Drug Administration, 2001).

Sensory evaluations of treated shrimps: After frozen storage, the samples were thawed and washed with tap water, wrapped in aluminum foil (3 shrimps each) and steamed at atmospheric pressure for $20 \mathrm{~min}$. They were served warm to the panelists. Prior to this, 18 assessors (aged 21-52; 7 males and 11 females) were prescreened for suitability and trained to develop their ability and hone their skills in detecting and identifying the differences among the samples. This was followed by three 6-hourly training sessions on quantitative descriptive analysis (Powers, 1988). The panelists developed the terminologies describing the attributes that were collectively chosen to represent the sensory characteristics for the shrimps. Reference samples were referred to for confirmation of the attributes as and when necessary. At each training session, the panelists were exposed to controlled and treated samples. They were trained to recognize the differences in the intensity of the attribute from its absence to its strongest presence. A sensory evaluation sheet was developed based on the attributes chosen and constructed as a $15.2 \mathrm{~cm}$ horizontal line with two word anchors placed at $12.7 \mathrm{~cm}$ from each end in an unstructured manner. Evaluation of a specific sensory attribute would be indicated by a vertical mark on the line. Fresh prawn sample was used as a control. At the end of each session, tests were conducted to evaluate the performance of each panelist (Meilgaard et al., 1991; Hootman, 1992; Stone and Sidel, 1993). The objective of the sensory test was to identify the most preferred or desired intensity of each of the attribute being evaluated caused by the effect of freezing and concentration of sodium lactate on the sensory qualities of shrimps. Thus a score was made for each of the attribute for its preference or desirability. Scores for preference start from the left anchor as having no preferred intensity of the attribute to the anchor on the right as having the strongest preferred or desired intensity of the attribute being judged.

Color measurement: $L^{*}, a^{*}, b^{*}$ color space values of frozen samples at various treatments were obtained using the multi-function spectrophotometer (Minolta CM-3500d, Osaka Japan). The instruments were calibrated against a zero calibration devices (CM-124) followed by a standard white reference tile (CM-A120). Approximately $12 \mathrm{~g}$ sample per treatment was placed into a Petri dish (CM-A128) and placed on target mask (for Petri dish) (CM-127). The target mask used limits the illumination area to the actual measurements area within the Petri dish. The corresponding L, a, b was obtained using the Spectramagic Version 2.11, 1998 (Minolta) software. The results were expressed as L* (lightness), $\mathrm{a}^{*}$ (degree of redness) and $\mathrm{b}^{*}$ (degree of yellowness) values. Color measurements were taken in quadruple and average values were taken for calculation. 
Statistical analysis: The bacterial count on shrimp samples were converted into logarithms of the number of Colony Forming Units $\mathrm{g}^{-1}\left(\log \mathrm{CFU} \mathrm{g}^{-1}\right)$ for statistical analysis. Analysis Of Variance (ANOVA) was performed using SPSS Version 15.0, 2006 Windows XP and comparisons of means were made using Tukey's test at the 95\% confidence level.

\section{RESULTS AND DISCUSSION}

Microbiological evaluation of shrimps after frozen storage: Sodium lactate solutions combined with freezing (block water) seems to be very effective against $V$. parahaemolyticus and $V$. cholerae. It is also effective towards Salmonella and E. coli in which each of the load was reduced to below $4 \log \mathrm{CFU} \mathrm{g}{ }^{-1}$ (Fig. 1). However, there is no significant difference ( $>0.05)$ in the effectiveness of sodium lactate in the case of reducing the number of pathogens in shrimps with increasing concentrations.

Information on the effect of sodium lactate on pathogenic bacteria during frozen storage is limited. Most studies were carried out during refrigeration $\left(4^{\circ} \mathrm{C}\right)$ temperatures or condition of low temperature abuse $\left(10^{\circ} \mathrm{C}\right)$ (Byrne et al., 2002). Silliker et al. (1980) have mentioned that Gram-negative pathogens such as Salmonella can be controlled by pH below 4.0, but low $\mathrm{pH}$ with combination of other factors such as low temperature are needed to control E. coli.

Vibrio parahaemolyticus is sensitive to low temperatures. The lowest temperature for growth of $V$. parahaemolyticus in laboratory media is at $5^{\circ} \mathrm{C}$. However, growth at low temperature is markedly affected by $\mathrm{pH}$. Byrne et al. (2002) used 4\% (w/v) sodium lactate in beef burger patties (inoculated with E. coli) during mincing and the formed patties were frozen and stored for 1 month. The results indicated that a synergistic effect exists between freezing and sodium lactate to reduce the overall risks posed to consumers by the presence of $E$. coli by reducing the pathogen survival during freezing and frozen storage of uncooked product (Byrne et al., 2002).

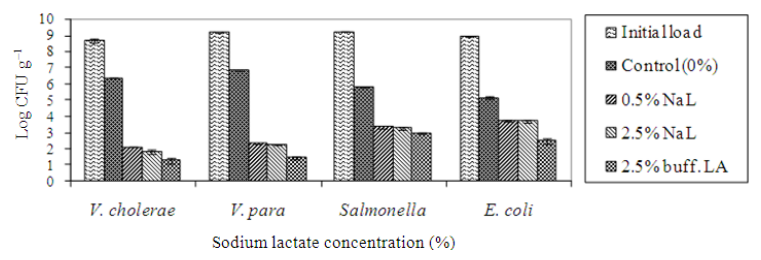

Fig. 1: Effect of sodium lactate and buffered LA in block water of frozen inoculated shrimps: NaL: Sodium lactate; LA: Lactic Acid
Buffered lactic acid had lower pH (4.70) than sodium lactate solutions ( $\mathrm{pH} 8.60)$. On the other hand the $\mathrm{pH}$ of sodium lactate decreased on to the buffered solution. According to Williams and Philips (1999) as the $\mathrm{pH}$ of sodium lactate decreased, concentration of undissociated lactic acid and antimicrobial properties increased. In this research buffered lactic acid $(2.5 \%$ $\mathrm{v} / \mathrm{v})$ displays a remarkable effect against all tested pathogens by bringing the load to 1.24 and $1.43 \log$ CFU $\mathrm{g}^{-1}$ for $V$. cholerae and $V$. parahaemolyticus and 2.46 and $2.94 \log \mathrm{CFU} \mathrm{g}{ }^{-1}$ for E. coli and S. enteritidis, respectively after 90 days storage at $-18^{\circ} \mathrm{C}(\mathrm{p} \leq 0.05)$.

As a result, depending upon the bacterial strain, sodium lactate appeared less bactericidal and more bacteriostatic. It is generally accepted that antibacterial effects of lactic acid are due to the ability of undissociated acid to act on bacterial cell membrane (Bogaert and Naidu, 2000). More of the acid would be undissociated at lower $\mathrm{pH}$ rather than neutral $\mathrm{pH}$. According to Long and Philips (2003) one possibility for antimicrobial activity of sodium lactate in meat products is that the undissociated form moves across the cell membrane, dissociates inside the cell thus acidifying the cell cytoplasm resulting in disruption of cell functions. However, at the $\mathrm{pH}$ of unfermented meat and meat products (usually about 6.0-6.5) sodium lactate is nearly fully dissociated with the undissociated form being at a very low concentration. The same situation would presumably apply in shrimps. In addition, the antimicrobial effects of lactates may due to their ability to lower water activity and to the inhibitory effects of the lactate ion (Koos and De, 1992; Mohamed et al., 2008).

Sensory evaluation of frozen shrimps treated with lactates: Frozen shrimps in $2.5 \%$ (v/v) buffered lactic acid gave reasonably high scores (9 per 15) (Fig. 2). Except for aroma the scores for the attributes analyzed for this product are almost similar to those frozen in water. It is recommended that for freezing purposes, $2.5 \%$ buffered lactic acid be used.

Color measurement: The color component of Penaeus merguiensis responded to various concentration of sodium lactate and buffered lactic acid during storage. The Lightness $\left(\mathrm{L}^{*}\right)$ was affected by the additives. It decreased for $0.5 \%(\mathrm{v} / \mathrm{v})$ sodium lactate and increased for $2.5 \%$ sodium lactate and $2.5 \%$ buffered lactic acid compared to control samples (Table 1). 


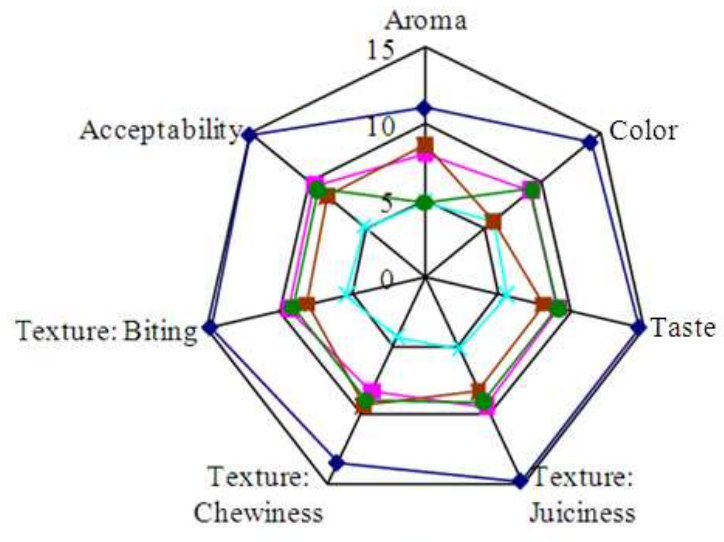

\begin{tabular}{|ll|}
\hline$\rightarrow-$ Fresh & - - Water \\
$\rightarrow-0.5 \% \mathrm{NaL}$ & $\rightarrow-2.5 \% \mathrm{NaL}$ \\
$--2.5 \%$ buffered LA & \\
\hline
\end{tabular}

Fig. 2: Sensory attribute scores of frozen shrimps treated with sodium lactate and buffered LA NaL: Sodium lactate; LA: Lactic Acid

Table 1: Effect of sodium lactate (Na.L) and buffered LA on color measurement of frozen shrimps ${ }^{1,2}$

\begin{tabular}{|c|c|c|c|c|c|}
\hline \multirow[b]{2}{*}{ Sample } & & & \multicolumn{3}{|l|}{ Color values } \\
\hline & & & $\mathrm{L}^{*}$ & $\mathrm{a}^{*}$ & $b^{*}$ \\
\hline \multirow[t]{2}{*}{ Control } & & & $46.69 \pm 0.10^{C}$ & $13.50 \pm 0.08^{\mathrm{A}}$ & $16.06 \pm 0.27^{\mathrm{A}}$ \\
\hline & Buff. LA & $2.5 \%$ & $50.81 \pm 0.35^{\mathrm{A}}$ & $6.29 \pm 0.73^{\mathrm{D}}$ & $12.70 \pm 1.43^{\mathrm{C}}$ \\
\hline \multirow[t]{2}{*}{ Treatment } & $\mathrm{Na} . \mathrm{L}$ & $0.5 \%$ & $45.08 \pm 0.14^{\mathrm{D}}$ & $9.51 \pm 0.09^{\mathrm{B}}$ & $14.84 \pm 0.36^{\mathrm{AB}}$ \\
\hline & & $2.5 \%$ & $48.07 \pm 0.10^{\mathrm{B}}$ & $7.64 \pm 0.07^{\mathrm{C}}$ & $13.24 \pm 0.66^{\mathrm{BC}}$ \\
\hline
\end{tabular}

${ }^{\mathrm{T}}$ : Mean values bearing same subscript within each treatment did not differ significantly ( $\leq 0.05) ;{ }^{2} \mathrm{NaL}$ : Sodium lactate; LA: Lactic Acid

Shafiur (1995) mentioned that the stability of pigments in foods is influenced by oxygen content, light exposure, oxidizing or reducing substance content, heavy metal content, water activity, $\mathrm{pH}$ and temperature (Powers, 1988). Moreover, Von Elba (1987) has also mentioned that water activity is the primary factor affecting pigment stability and/or color of food products (Von Elba, 1987). The major classes of pigments responsible for color in food products are: Chlorophylls, carotenoids, anthocyanins and betalains. Detailed stability of the above pigments in foods is provided by Von Elbe (1987). Furthermore, color can change as a result of storage time, storage temperature and exposure to light (Zachariah and Stterlee, 1973).

There are a few studies on color measurements of seafood products affected by additives during storage. Williams and Rodrick (1995) reported that treatment of black sea bass and mullet with $2.0 \%(\mathrm{v} / \mathrm{v})$ sodium lactate resulted in more color stability at $1.0 \%$ concentration of sodium lactate. In the present study degree of greenness or redness color $\left(\mathrm{a}^{*}\right)$ value decreased for all treatments compared to control samples (distilled water treated). This may be due to degradation of pigments due to changes in carotenoids.

For degree of yellowness or brownness ( $\left.b^{*}\right)$ statistical analysis revealed no significant difference $(\mathrm{p}>0.05)$ between control treatments and $0.5 \%(\mathrm{v} / \mathrm{v})$ sodium lactate. Also no significant effect was seen between $2.5 \%(\mathrm{v} / \mathrm{v})$ sodium lactate and $2.5 \%$ buffered lactic acid.

\section{CONCLUSION}

The results also indicated that there was synergistic effect between frozen storage combined with $2.5 \%$ $(\mathrm{v} / \mathrm{v})$ buffered LA which resulted in a great significant reductions $(\mathrm{p} \leq 0.05)$ approximately $5.11,5.39,2.86$ and $2.66 \log \mathrm{CFU} \mathrm{g}{ }^{-1}$ in the number of colonies of $V$. cholerae, $V$. parahaemolyticus, Salmonella enteritidis and E. coli $\mathrm{O} 157: \mathrm{H} 7$, respectively during 90 days storage at $-18^{\circ} \mathrm{C}$. Although there was a sharp reduction in Vibrios during frozen storage however, as the results show these organisms persisted in shrimps stored at$18^{\circ} \mathrm{C}$ even after 3 months.

The effectiveness of sodium lactate solutions were uniform as the concentrations increased. The study successfully demonstrated the use of buffered lactic acid as antimicrobial solution in freezing to control of microbial quality of shrimps. Therefore, $2.5 \%(\mathrm{v} / \mathrm{v})$ buffered lactic acid was recommended to be used for shrimps without adversely interfering with the sensory quality of products. In addition, results from color measurement demonstrated that lightness $\left(\mathrm{L}^{*}\right)$ was affected by the additives. Lightness significantly increased for buffered lactic acid during storage. $a^{*}$ and $b^{*}$ value also exhibited significant $(p \leq 0.05)$ changes in shrimps during storage in all treatments.

Practical applications: One of the practical application of the present study is the use of antibacterial ices containing 2.5\% (v/v) buffered lactic acid in seafood processing industries, during processing line, freezing and/or storage process for improving the preservation methods and keeping quality of products by reducing the risks posed to consumers and inhibition of pathogenic bacteria particularly Vibrio spp. which can be found from marine products.

Future works: After frozen storage and during thawing, visually it was observed that buffered lactic acid was able to prevent the black spots on the surface of the shrimps shell compared with the control samples. Nowadays black spot in the seafood factories is wellknown and it can play an important role for acceptability of products for the consumers. For the 
future work it would be suggested study on the effects of buffered LA to control melanosis during handling and processing of shrimp.

\section{ACKNOWLEDGEMENT}

We gratefully acknowledge from PURAC Asian Pacific Pte. Ltd. Singapore for financial grant to carry out this project.

\section{REFERENCES}

Bogaert, J.C. and A.S. Naidu, 2000. AcidAntimicrobials: Lactic Acid. In: Natural Food Antimicrobial Systems, Naidu, A.S. (Ed.). CRC Press, New York.

Byrne, C.M., D.J. Bolton, J.J. Sheridan, I.S. Blair and D.A. McDowell, 2002. Determination of the effect of sodium lactate on the survival and heat resistance of Escherichia coli $\mathrm{O} 157: \mathrm{H} 7$ in two commercial beef patty formulations. Food Microbiol., 19: 211-219.

Food and Drug Administration, (FDA), 2001. Methods for specific pathogens: Escherichia coli, Salmonella and Vibrio. 8th Edn., Bacteriological Analytical Manual (BAM), US.

http://www.cfsan.fda.gov/ ebam/bam-toc.html

Hootman, R.C., 1992. Manual on Descriptive Analysis Testing for Sensory Evaluation (ASTM Manual Series: MNL 13). American Society for Testing and Materials. ASTM Publication Code No (PCN) 28-013092-36.

Long, C. and C.A. Phillips, 2003. The effect of sodium citrate, sodium lactate and nisin on the survival of Arcobacter butzleri NCTC 12481 on chicken. Food Microbiol., 20: 495-502.

Koos, I.J. and T. De, 1992. Lactic acid and lactates. Preservation of food products with natural ingredients. Food Market. Technol., 6: 5-11.

Meilgaard, M., G.V. Civille and B.T. Carr, 1991. Sensory Evaluation Techniques. CRC Press, Boca Raton, Florida, pp: 345.

Mohamed, B. Jamilah, K.A. Abbas and R. Abdul Rahman, 2008. A review on some organic acids additives as shelf life extenders of fresh beef cuts. Am. J. Agric. Biol. Sci., 3: 566-574.
Papadopoulos, L.S., R.K. Miller, L.J. Ringer and H.R. Cross, 1991. Sodium lactate effect on sensory characteristics, cooked meat color and chemical composition. J. Food Sci., 56: 6-21.

Powers, J.J., 1988. Current Practices and Application of Descriptive Methods. In: Sensory Analysis of Foods, Piggott, J.R. (Ed.). Elsevier Science Publishers, New York, pp: 187-266.

Shafiur, R., 1995. Water Activity and Sorption Properties of Foods. In: Food Properties Handbook, CRC Press, Boca Raton, Florida.

Shelef, L.A., 1994. Antimicrobial effects of lactate: A review. J. Food Protect., 57: 445-450.

Silliker, J.H., R.P. Elliott, A.C. Baird-Parker, F.L. Bryan and J.H.B. Christian et al., 1980. Microbial Ecology of Foods. Academic Press, New York.

Stekelenburg, F.K. and M.L.T. Kant-Muermans, 2001. Effects of sodium lactate and other additives in a cooked ham product on sensory quality and development of a strain of Lactobacillus curvatus and Listeria monocytogenes. Int. J. Food Microbiol., 66: 197-203.

Stone, H. and J.L. Sidel, 1993. Sensory Evaluation Practices. Academic Press, New York, pp: 338.

Von Elba, J.H., 1987. Influence of Water Activity on Pigment Stability in Food Products. In: Water Activity: Theory and Applications to Food, Rockland, L.B. and L.R. Beuchat (Eds.). Marcel Dekker Inc., New York.

Williams, S.K. and G.E. Rodrick, 1995. The antimicrobial effects of lactic acid, acetic acid and sodium lactate on storage stability of fresh black sea bass and mullet fillets stored under simulated retail conditions. Food Microbiol., 39: 392-396.

Williams, S.K. and K. Philips, 1999. Sodium lactate affects sensory and objective characteristics of tray-packed broiler chicken breast meat. J. Poultry Sci., 77: 765-769.

Zachariah, N.Y. and L.D. Stterlee, 1973. Effect of light, $\mathrm{pH}$ and buffer strength on the autoxidation of porcine, ovine and bovine myoglobins at freezing temperature. Microbiol. Rev., 55: 476-511. 